\title{
PERAN ON THE JOB TRAINING TERHADAP PENINGKATAN KINERJA KARYAWAN DI PT. XYZ
}

\section{The Role of On The Job Training Towards Performance Improvement of Employees in PT. XYZ}

\author{
Arbania Fitriani \\ Fakultas Psikologi Universitas Esa Unggul
}

Diterima tanggal 04 Desember 2019/ Disetujui tanggal 11 Desember 2019

\begin{abstract}
Nowadays, training is a very important factor for organizations because it will increase effectiveness and efficiency not only for individuals but for organizations. Many things affect performance, but the most important factor in improving performance is training. This study aims to evaluate On The Job Training design implementation at PT YXZ and see how the variables in the OJT design contribute to improving employee performance. Sampling technique method is probability random sampling with the Slovin formula according to the number of employees of each unit. The population in this study were all permanent employees with a total of 1,665. Samples were taken from various positions and tenure. The number of samples obtained was 323 employees. The results of the validity and reliability test are known that the Cronbach's Alpha value of each indicator is above 0.9 so it can be said that all indicators have a very good level of reliability. The Pearson Product Moment correlation value is above 0.8 so that the measuring instrument is considered valid. Based on the results of the frequency distribution, it was found that according to OJT, $70.51 \%$ respondents had been implemented quite well. The results of the simultaneous regression test resulted in a $P_{\text {value }}=0.000(P<0.05)$ which means that Ho was rejected and $\mathrm{Ha}$ was accepted. The value of how much influence the overall indicator on the effectiveness of OJT is displayed in the regression model as follows, OJT Factor Value $=2,422+0.015$ (total value of OJT Implementation items). The results of this study prove that the design variables in OJT have a significant influence in to performance.
\end{abstract}

Keywords: training; performance; on the job training; employee

Saat ini, training menjadi faktor yang sangat penting bagi organisasi karena akan meningkatkan efektivitas dan efesiensi bukan hanya bagi individu tapi bagi organisasi. Banyak hal yang mempengaruhi kinerja, namun faktor yang paling penting dalam meningkatkan kinerja adalah training. Penelitian ini bertujuan untuk melakukan evaluasi terhadap desain On The Job Training pada PT YXZ dan melihat bagaimana variabel dalam desain OJT tersebut memberikan kontribusinya dalam peningkatan kinerja karyawan. Teknik sampling yang digunakan adalah probability random sampling dengan jumlah sampel sesuai dengan rumus Slovin menurut jumlah karyawan dari tiap unit. Populasi dalam penelitian ini adalah segenap karyawan permanen dengan jumlah 1.665. Sampel diambil dari berbagai jabatan dan masa kerja. Jumlah sampel yang didapat sebanyak 323 kayawan. Hasil uji validitas dan reliabilitas diketahui bahwa Nilai Cronbach's Alpha tiap indikator diatas nilai 0,9 sehingga dapat dikatakan semua indikator memiliki tingkat reliabilitas yang sangat baik. Adapun nilai korelasi Pearson Product Moment di atas 0.8 sehingga alat ukur dianggap valid. Berdasarkan hasil distribusi frekuensi, didapatkan bahwa menurut para responden $O J T$ telah 70,51\% terimplementasi dengan cukup baik. Hasil uji regresi serentak menghasilkan $\mathrm{P}_{\text {value }}=0.000(\mathrm{P}<0.05)$ yang berarti $\mathrm{H}_{0}$ ditolak dan Ha diterima. Nilai berapa besar pengaruh keseluruhan indikator terhadap efektivitas OJT ditampilkan dalam model regresi sebagai berikut. Nilai Faktor OJT= $2.422+0.015$ (total nilai item Implementasi OJT). Hasil penelitian ini membuktikan bahwa desain variabel dalam OJT memberikan pengaruh terhadap kinerja.

Kata kunci: pelatihan; kinerja; on the job training; karyawan

*Korespondensi: arbania@esaunggul.ac.id 


\section{PENDAHULUAN}

Pengembangan karir adalah topik nomor satu di banyak pikiran karyawan. Pada masa kini, kesuksesan organisasi dapat bergantung pada apakah karyawan terlibat dalam pembelajaran dan pengembangan diri atau tidak. Menurut survei nasional baru-baru ini, penyumbang terbesar dari perputaran karyawan bukanlah gaji atau supervisi, tetapi "apakah terdapat peluang yang memadai untuk pengembangan profesional." Para pemimpin yang menjalankan fungsinya secara efektif menganggap diri mereka bertanggung jawab untuk menyediakan peluang tersebut. Namun, sementara ada banyak tindakan yang dapat dilakukan oleh para pemimpin, ada juga metode yang harus mereka ikuti jika mereka ingin para karyawan terlibat dalam pembelajaran dan pengembangan mereka sendiri (Bullock, 2012).

Pengembangan diri yang paling umum dilakukan di hampir seluruh organisasi adalah melalui training.

Gambar 1. Siklus Desain Training

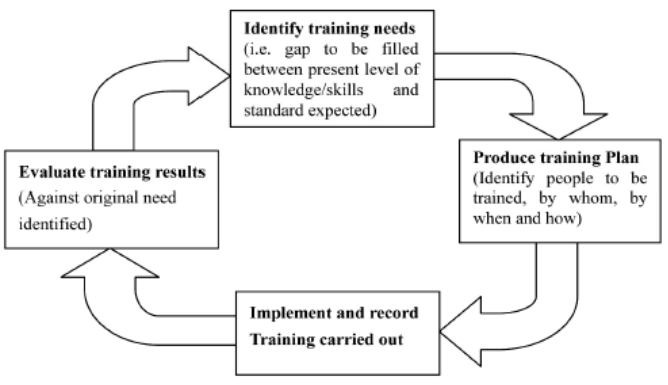

Menurut (Bramley, 2003) training adalah proses yang memfasilitasi kegiatan belajar untuk mendorong karyawan agar bekerja secara lebih efektif. Training membantu karyawan untuk mendapatkan pandangan yang jelas terhadap apa yang mereka kerjakan (Karim, Huda, \& Khan, 2012). Menurut (Pilbeam \& Corbridge, 2002) terdapat 4 tahapan utama dari proses training yakni identifikasi kebutuhan training, perencanaan dan desain training, pelaksanaan training, dan evaluasi training seperti gambar pada siklus di bawah.
Penelitian ini berfokus pada evaluasi implementasi hasil training.

Saat ini, training menjadi faktor yang sangat penting bagi organisasi karena akan meningkatkan efektivitas dan efesiensi bukan hanya bagi individu tapi bagi organisasi. Banyak hal yang mempengaruhi kinerja, namun faktor yang paling penting dalam meningkatkan kinerja adalah training. Kinerja organisasi tergantung kepada kinerja karyawannya sebab peran manusia sebagai asset perusahaan memainkan peran yang sangat penting bagi pertumbuhan dan kinerja organisasi itu sendiri (Abdul, Khan, Khan, \& Khan, 2011). Banyak peneliti juga menemukan hasil yang sama mengenai peran penting training bagi kinerja karyawan yang akan berdampak pada kinerja organisasi. Salah satu hasil penelitian yang dilakukan oleh (Iftikhar \& Din, 2009) pada sektor kesehatan menunjukkan hasil yang siginifikan antara peran training and development terhadap peningkatan kinerja.

Training hanya akan efektif dalam pencapaian tujuan organisasi apabila di padukan antara kebutuhan karyawan dan organisasi itu sendiri (Lee, Esen, \& DiNicola, 2017). Cara untuk menyesuaikan antara kebutuhan organisasi dengan kebutuhan individu adalah melalui on the job training. On-the-Job Training (OJT) dapat didefinisikan sebagai proses yang dirancang sebagai media belajar, pengembangan, dan pertumbuhan pribadi melalui pengalaman kerja nyata. Pemimpin memainkan peran penting dalam OJT, yaitu bukan berfokus pada mengajar, melainkan memfasilitasi pembelajaran dengan melibatkan karyawannya dalam proses pengembangan. Ini berarti menyediakan sumber daya (misalnya, tugas, informasi, umpan balik, akses kepada pihak-pihak terkait, dan counseling one-on-one) dan dukungan selama proses tersebut.

OJT merupakan upaya untuk implementasi hasil yang diperoleh dari training. Untuk itu, desain dari sebuah program training dan implementasinya dalam OJT menjadi sangat penting karena akan mempengaruhi hasil dari program pengembangan tersebut. Hal ini sejalan dengan pendapat (Amstrong, 2000) bahwa 
penting bagi organisasi untuk mendesain training dengan hati-hati. Desain training haruslah sesuai dengan kebutuhan karyawan (Ginsberg, 1997). Organisasi yang mengembangkan desain training yang baik akan memperoleh hasil yang baik pula (Partlow, 1996). Hal ini menunjukkan bahwa desain training memainkan peranan yang paling penting dimana desain training yang buruk hanya akan membuang waktu dan uang (Tsaur \& Lin, 2004).

Merujuk pada hasil penelitian tersebut di atas, maka peneliti bermaksud untuk melakukan evaluasi terhadap desain On The Job Training pada PT YXZ dan melihat bagaimana variabel dalam desain OJT tersebut memberikan kontribusinya dalam peningkatan kinerja karyawan. PT XYZ adalah perusahaan manufaktur yang bergerak dalam bidang otomotif. PT XYZ telah berkiprah lebih dari 40 tahun di Indonesia. Dalam perjalanannya PT XYZ telah memproduksi mobil, mesin, komponen serta diesel dan jig. Selain untuk memenuhi kebutuhan dalam negeri, keempat jenis produk ini juga diekspor ke berbagai negara.

Terdapat 4 desain variabel OJT yang akan di diteliti implementasinya. Variabel tersebut antara lain Identify Suitable Work, Assign Work, Monitor and Lead to Complete Work, Give a Sense of Achievement (Personal Growth). Dari keempat desain variabel tersebut akan dilihat secara serentak dan per desain variabel akan perannya terhadap peningkatan kinerja karyawan di PT XYZ. Alat ukur yang dikembangkan merujuk pada level evaluasi Kirkpatrick pada level 3 yakni implementasi training melalui proses OJT yang dibagi ke dalam 4 desain ("Kirkpatrick Level 3 Survey Questions," n.d.)
Perumusan masalah dan teknik uji validitas reliabilitas

Penelitian ini menggunakan metodologi kuantitatif non-eksperimental / EPF dengan langkah sebagai berikut:

1. Perumusan masalah dan penyusunan hipotesis. Dengan merujuk pada latar belakang permasalahan, maka pertanyaan penelitian ini adalah,

a. Sejauh mana OJT telah diimplementasikan di PT XYZ ?

b. Apakah terdapat pengaruh yang positif dan signifikan terhadap kinerja?

Berdasarkan pertanyaan tersebut, maka hipotesis dalam penelitian ini adalah

Ha: Terdapat pengaruh yang positif dan signifikan antara OJT dan kinerja

Ho: Tidak terdapat pengaruh yang positif dan signifikan antara OJT dan kinerja

2. Penetapan Instrumen ukur meliputi penyusunan operasionalisasi konstruk dan item kuesioner. Sebelum memulai pengumpulan data secara kuantitatif, dilakukan perumusan secara literatur dari sumber-sumber yang telah dikaji, serta $F G D$ expert dari pihak manajemen untuk memberi gambaran hal-hal apa yang dapat menjadi alat ukur OJT hingga menemukan item-item pernyataan yang digunakan dalam mengukur implementasi dari OJT berdasarkan desain dari 4 variabel. IV dalam penelitian ini adalah kompetensi OJT dan DV adalah Kinerja. Untuk IV kemudian diuji dengan menggunakan alat ukur kuesioner dan FGD dimana masingmasing dari 4 desain variabel OJT dijadikan variabel bebas turunan yang akan diuji pengaruhnya terhadap DV. Sementara untuk mengukur DV digunakan pertanyaan dalam bentuk angket yang mengukur kinerja nyata dari responden dan bagaimana mereka memberikan penilaian peran OJT terhadap pencapaian kinerjanya. Adapun skema alat ukur dan teknik pengukuran berdasarkan gambar berikut.

\section{METODE PENELITIAN}


Versi Online: http://journal.ubm.ac.id/index.php/psibernetika DOI: http://dx.doi.org/ 10.30813/psibernetika.v12i2.1752 Hasil Penelitian

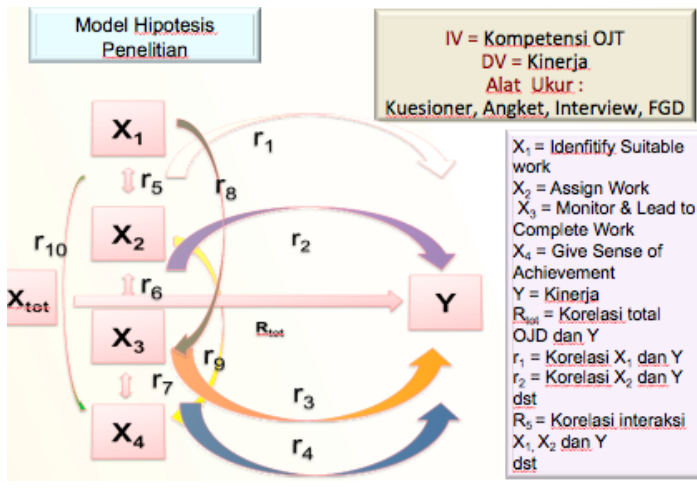

Berdasarkan hasil studi dan komparasi terhadap berbagai sumber dan tentunya berdasarkan kondisi lingkup kerja PT XYZ, didapatkan 100 item untuk mengukur IV (Form A) dan 8 item untuk mengukur DV (form B) yang nantinya diharapkan dapat memberikan gambaran terhadap efektivitas $O J \mathrm{~T}$ melalui kompetensi para mentor dalam mengimplementasikan Identify Suitable Work, Assign Work, Monitor and Lead to Complete Work, Give a Sense of Achievement (Personal Growth). Validitas dan reliabiltas alat ukur di dapatkan melalui Pilot Test yang dilakukan dengan mengambil 31 orang sebagai responden. Untuk menjamin akurasi alat ukur, maka peneliti juga kembali menguji validitas dan reliabilitas alat ukur dengan menggunakan sampel terpakai yakni sebanyak 219 responden. Setelah pengujian validitas dan reliabilitas lalu dipilih 39 item yang memiliki indeks internal konsistensi yang tertinggi untuk kemudian dipakai sebagai alat ukur final.

Uji validitas dan pemeriksaan reliabilitas digunakan untuk mengukur tingkat akurasi dan presisi item-item yang disusun dalam pilot test ini dalam mengukur efektivitas $O J T$.

Selanjutnya dilakukan uji validitas untuk melihat tingkat validitas seluruh item dalam semua indikator. Digunakan uji korelasi pearson product moment untuk uji validasi dengan hipotesis sebagai berikut:

$$
\begin{aligned}
\mathrm{H}_{0}= & \text { tidak ada korelasi antara variabel } \\
& \text { ke } i \text { dengan total nilai (pernyataan } \\
& \text { tidak valid) }
\end{aligned}
$$

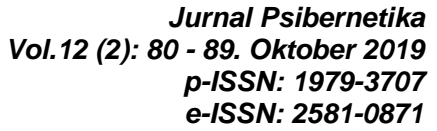

$\mathrm{H}_{1}=$ ada korelasi antara variabel ke $i$ dengan total nilai (pernyataan valid)

Nilai Cronbach's Alpha tiap indikator nilai 0,9 sehingga dapat dikatakan semua indikator memiliki tingkat reliabilitas yang sangat baik. Adapun nilai korelasi Pearson Product Moment di atas 0.8 sehingga alat ukur dianggap valid.

Koefisien

Cronbach Alpha merupakan salah satu uji reliabilitas instrument yang banyak digunakan. Metode lainnya adalah Confirmatory Faktor Analysis (CFA). Terdapat beberapa asumsi yang harus dipenuhi sebelum melakukan $C F A$. Asumsi yang harus terpenuhi adalah antar item dan indikator harus saling berkorelasi kuat secara bivariate. Selain itu, antar variabel harus saling berkorelasi secara multivariate. Hal tersebut diuji dengan Uji Bartlett's dan identifikasi kecukupan data dengan Keiser-Meyer-Olkin (KMO).

Berikut pengujian Bartlett dilakukan dengan statistic uji Chi-square dengan menggunakan taraf signifikan 5\%.

$\mathrm{H}_{0}: \rho=0$ (Data dari On the Job Training PT XYZ tidak memiliki hubungan secara multivariat)

$\mathrm{H}_{1}: \rho \neq 0$ (Data dari On the Job Training PT XYZ memiliki hubungan secara multivariat)

Serta untuk identifikasi kecukupan data untuk seluruh indikator dengan menggunakan Keiser-Meyer-Olkin (KMO). Data dikatakan cukup untuk difaktorkan apabila memiliki nilai KMO lebih besar dari 0,5. Hasil analisis ditampilkan dalam tabel berikut.

Tabel 1 Tabel KMO Variabel OJT

\begin{tabular}{lccc}
\hline \multicolumn{1}{c}{ Indikator } & KMO & $\begin{array}{c}\text { Appr. Chi } \\
\text { Square }\end{array}$ & $\begin{array}{c}\text { Signi- } \\
\text { fikansi }\end{array}$ \\
\hline $\begin{array}{l}\text { Identify } \\
\text { Suitable Work }\end{array}$ & 0.474 & 774,488 & 0.00 \\
$\begin{array}{l}\text { Assign Work } \\
\text { Monitor and }\end{array}$ & 0.738 & 845,733 & 0.00 \\
$\begin{array}{l}\text { Lead to } \\
\text { Complete Work }\end{array}$ & 0.516 & 860,522 & 0.00 \\
$\begin{array}{l}\text { Give a Sense of } \\
\text { Achievement } \\
\text { (Personal }\end{array}$ & 0.678 & 676,680 & 0.00 \\
Growth) & & & \\
\hline
\end{tabular}


Berdasarkan hasil uji independensi pada Tabel di atas terlihat bahwa signifikansi Chi-square dari Bartlett's Test adalah sebesar 0,000 yang berarti signifikansi kurang dari $\alpha$ sebesar 0,05 . Sehingga keputusannya adalah Tolak $\mathrm{H}_{0}$, maka disimpulkan bahwa antar data antar variabel adalah dependen atau memiliki hubungan secara multivariat.

Diketahui pula bahwa nilai KaiserMayer-Olkin (KMO) dari variabel Identify Suitable Work kurang dari 0.5, hal tersebut berarti data dari variabel tersebut tidak cukup untuk difaktorkan. Hal tersebut menyebabkan Seluruh variabel tidak dapat dilakukan analisis faktor untuk melihat pembagian faktor dari hasil survey. Namun, berdasarkan hasil pengamatan reliabilitas dan pengujian validitas, data pilot test OJT PT XYZ dinyatakan valid dan reliabel sehingga dapat dilanjutkan ke analisis berikutnya.

\section{Penetapan teknik sampling dan responden}

Teknik sampling yang digunakan adalah Sampling Acak Probabilitas (probability random sampling) dengan jumlah sampel sesuai dengan rumus Slovin menurut jumlah karyawan dari tiap unit. Adapun penelitian ini menggunakan rumus Slovin karena dalam penarikan sampel, jumlahnya harus representative agar hasil penelitian dapat digeneralisasikan dan perhitungannya pun tidak memerlukan tabel jumlah sampel, namun dapat dilakukan dengan rumus dan perhitungan sederhana. Rumus Slovin dijabarkan sebagai berikut:

$$
n=\frac{N}{1+e^{2}}
$$

Populasi dalam penelitian ini adalah segenap karyawan permanen dengan jumlah 1.665. Sampel diambil dari berbagai jabatan dan masa kerja. Jumlah sampel yang didapat sebanyak 323 pegawai dengan metode rumus Slovin. Untuk kegiatan Focus Group Discussion guna melakukan pengukuran kualitatif terhadap tingkat efektivitas $O J T$, peserta $F G D$ diambil dari sampel yang terpilih menjadi responden survei sesuai dengan kebutuhan penggalian informasi dan kesanggupan peserta terpilih.

$$
\text { Adapun responden yang }
$$
mengembalikan kuesioner dan angket dapat dilihat pada gambar berikut:

Gambar 4. Sebaran Data Sampling

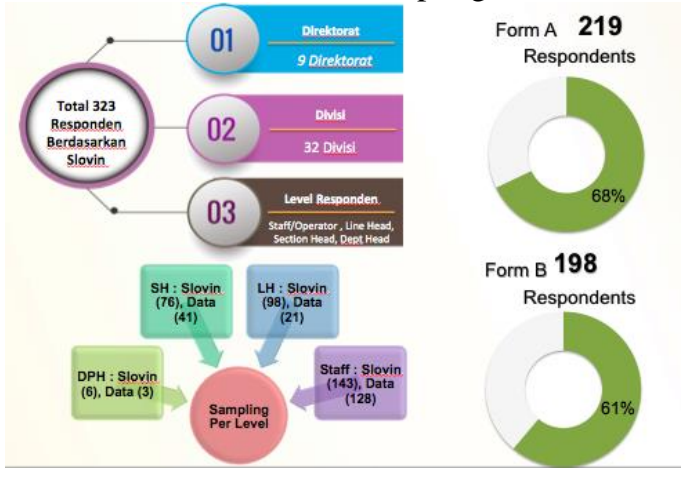

\section{Pengumpulan data}

Pengumpulan data dilakukan dengan menggunakan dua cara yaitu kuesioner dan angket untuk mendapat data kuantitatif dan kualitatif dan Focus Group Discussion untuk menggali pemahaman yang lebih luas dalam menginterpretasi data. FGD dilakukan untuk mendapatkan informasi yang lebih dalam terhadap suatu hal yang dianggap krusial untuk digali lebih lanjut. Pengumpulan data dengan $F G D$ ini sifatnya kualitatif dan memperkaya hasil analisa statistik dari data kuesioner sehingga analisa dan rekomendasi dapat lebih kaya dan akurat serta terpercaya dalam pengambilan keputusan bagi pihak manajemen.

\section{Analisis data survei}

Data yang sudah terkumpul selanjutnya diolah dengan menggunakan metode statistik melalui pendekatan distribusi frekuensi dan analisa regresi berganda. Distribusi frekuensi melihat gambaran penyebaran jawaban oleh responden untuk kemudian dianalisa prosentase implementasi OJT. Sedangkan, analisis regresi berganda digunakan untuk melihat pengaruh OJT terhadap kinerja 
Versi Online: http://journal.ubm.ac.id/index.php/psibernetika DOI: http://dx.doi.org/ 10.30813/psibernetika.v12i2.1752 Hasil Penelitian

dengan mengkorelasikan antara Form A dan Form B.

\section{HASIL DAN PEMBAHASAN}

\section{Uji homogenitas data dan normalitas data}

Uji homogenitas dilakukan untuk melihat apakah data yang diambil memiliki varians populasi yang sama. Data yang memiliki varians yang sama mengindikasikan responden berasal dari lingkup yang seragam sehingga menimbulkan interpretasi yang sama dalam merespon penelitian yang dilakukan. Hal tersebut mengakibatkan hasil dari penelitian ini dapat disimpulkan dan diimplementasikan kepada seluruh level yang terkait.

Berikut pengujian Bartlett dilakukan dengan statistic uji Chi-square dengan menggunakan taraf signifikan 0,05 .

Hipotesis:

$\mathrm{H}_{0}$ : data dari 39 item homogen

$\mathrm{H}_{1}$ : data dari 39 item tidak homogen

Tabel 2. Indeks Homogenitas Data

\begin{tabular}{ll}
\hline \multicolumn{2}{c}{ Bartlett's Test } \\
\hline Approx. Chi-Square & 1.214 \\
Sig. & 0.562 \\
\hline
\end{tabular}

Berdasarkan pengujian di atas, didapatkan nilai signifikansi sebesar 0,562 yang lebih besar dari taraf signifikan sehingga hipotesis yang yang diterima adalah $\mathrm{H}_{0}$ yaitu data dari 39 item homogen. Selanjutnya dilakukan pengujian untuk mengidentifikasi apakah data hasil survey berdistribusi normal. Pengujian distribusi normal multivariat secara inferensia dilakukan dengan uji korelasi antara $d j^{2}$ yang telah diurutkan dengan nilai chi-squrenya. Hipotesis yang digunakan sebagai berikut:

$H_{0}$ :Seluruh item memenuhi asumsi distribusi normal multivariat

$H_{1}$ : seluruh item tidak memenuhi asumsi distribusi normal multivariat
Jurnal Psibernetika

Vol.12 (2): 80 - 89 . Oktober 2019

p-ISSN: 1979-3707

e-ISSN: 2581-0871

Hasil pengujian didapatkan nilai signifikansi 0.907 lebih dari taraf signifikan 0.05 yang menghasilkan keputusan $H_{0}$ gagal ditolak. Hal tersebut menunjukkan seluruh item memenuhi asumsi distribusi normal multivariat.

\section{Persentase implementasi $O J T$}

Analisis ini dilakukan untuk melihat berapa kebaikan Implementasi OJT berdasarkan jawaban responden dalam 39 item. Analisis ini akan dibagi menjadi tiga bagian, yaitu Total Implementasi OJT, Implementasi OJT per Item dan Implementasi $O J T$ per indikator.

Analisis total implementasi OJT dianalisis dengan membuat nilai rata-rata dari total skor yang mencakup keseluruhan item lalu dibagi dengan skor maksimal untuk mendapatkan persentase kebaikan. Hasil analisis ditampilkan sebagai berikut:

Gambar 5. Prosentase Implentasi OJT

\section{PERSENTASE IMPLEMENTASI PELAKSANAAN OJT}

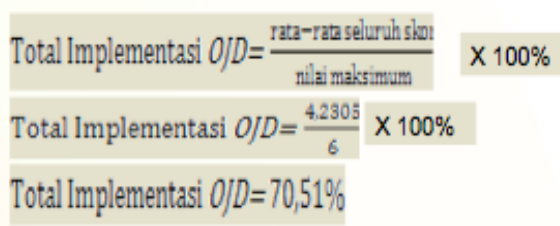

Berdasarkan analisis di atas, didapatkan bahwa menurut para responden OJT telah 70,51\% terimplementasi dengan cukup baik.

Selanjutnya dilakukan analisa implementasi OJT per item dan ditemukan 3 besar aspek yang telah diimplementasikan paling sering dan 3 besar aspek yang masih kurang diimplementasikan sebagai berikut, Tiga item yang memberikan persentase tertinggi, yaitu: 1). Tugas yang saya jalankan membuat saya dapat mengembangkan kemampuan saya (item nomor 6) dengan persentase 77,093\%; 2). Atasan saya memberikan kesempatan untuk berdiskusi mengenai proyek sebelum ditugaskan kepada saya (item nomor 5) dengan persentase $76,941 \%$; 3 ). Tugas yang diberikan kepada saya membuat saya 
merasa tertantang (item nomor 5) dengan persentase $75,342 \%$.

Sedangkan tiga item dengan persentase terendah yaitu: 1). Atasan saya biasanya langsung mendiktekan cara untuk mengatasi permasalahan berdasarkan versi atasan tanpa mendorong saya terlebih dahulu untuk mencari jawaban atas permasalahan yang saya hadapi (item nomor 27) dengan persentase $61,796 \%$; 2). Atasan memberikan umpan balik secara reguler, terjadwal, dan privat untuk mengevaluasi Implementasi tugas saya (item nomor 33) dengan persentase $65,525 \%$; 3). Saya hanya bertemu dengan atasan di awal penugasan dan setelah tugas selesai untuk pelaporan hasil (item nomor 24 ) dengan persentase $65,982 \%$.

Selanjutnya, dilihat persentase kebaikan Implementasi dari masing-masing indikator. Analisis ini menggunakan total nilai per indikator. Hasil analisis ditampilkan sebagai berikut.

Gambar 6. Prosentase Implementasi OJT Per Variabel

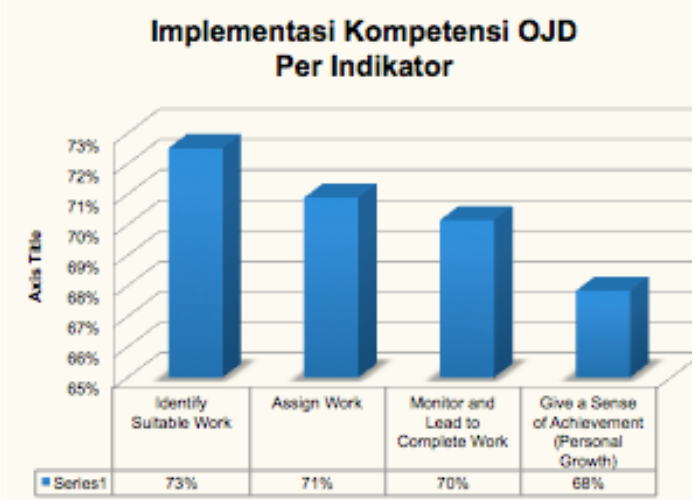

Diketahui proses Identify Suitable Work dinilai Implementasinya telah baik oleh responden karena menghasilkan persentase terbesar dari keempat indikator yaitu sebesar 72,514\%. Sedangkan indikator yang persentasenya terendah adalah Give a Sense of Achievement (Personal Growth) dengan persentase $67,842 \%$.

Uji pengaruh metode implementasi $O J T$ terhadap kinerja
Pada analisis ini, digunakan uji regresi untuk melihat besar pengaruh metode Implementasi yang dijabarkan dengan indikator Identify Suitable Work, Assign Work, Monitor and Lead to Complete Work, Give a Sense of Achievement (Personal Growth) kinerja menurut penilaian responden.

Uji ini dilakukan untuk melihat apakah indikator Identify Suitable Work, Assign Work, Monitor and Lead to Complete Work, Give a Sense of Achievement (Personal Growth) memberikan pengaruh secara signifikan apabila seluruh tahapan tersebut dilakukan. Metode yang digunakan adalah regresi linier sederhana dengan variabel dependen kolom isian Internal: On The Job Training (dukungan dan bimbingan atasan) di Form $\mathrm{B}$, sedangkan variabel independent adalah total jawaban responden pada 39 item di Form A.

Terlebih dahulu dilakukan pengujian serentak, yaitu pengujian signifikansi model regresi. Hipotesis yang digunakan dalam pengujian ini adalah sebagai berikut.

$\mathrm{H}_{0}$ : seluruh item Implementasi $O J T$ tidak berpengaruh signifikan terhadap hasil OJT

$\mathrm{H}_{1}$ : minimal ada 1 item atau indikator yang berpengaruh signifikan terhadap hasil $O J T$

Taraf signifikan : $\alpha=0.05$

Daerah kritis $\quad \mathrm{H}_{0}$ ditolak jika $\mathrm{P}_{\text {value }}<\alpha$ atau $F_{\text {hitung }}>F_{\text {tabel }}$

Dengan $F_{\text {tabel }}=F_{(0.95,39,154)}$

Tabel 4 Indeks Regresi Serentak Skor Total

\begin{tabular}{cccr}
\hline $\begin{array}{c}\text { Mean } \\
\text { Square }\end{array}$ & $\mathrm{F}_{\text {hitung }}$ & $\mathrm{F}_{\text {tabel }}$ & $\mathrm{P}_{\text {value }}$ \\
\hline 35.683 & 50.934 & 1.478 & $\begin{array}{r}0.0 \\
00\end{array}$ \\
\hline
\end{tabular}

Pengujian serentak menghasilkan $\mathrm{P}_{\text {value }}$ kurang dari 0.05 yang berarti $\mathrm{H}_{0}$ ditolak. Hal tersebut menunjukan bahwa minimal ada 1 item atau indikator yang berpengaruh signifikan terhadap hasil OJT. Nilai berapa besar pengaruh keseluruhan indikator terhadap efektivitas OJT ditampilkan dalam model regresi sebagai berikut. 
Versi Online: http://journal.ubm.ac.id/index.php/psibernetika DOI: http://dx.doi.org/ 10.30813/psibernetika.v12i2.1752 Hasil Penelitian

\begin{tabular}{lcccc}
\hline \multirow{2}{*}{ Model } & \multicolumn{4}{c}{ Unstandardized Coefficients } \\
\cline { 2 - 5 } & $B$ & $\begin{array}{c}\text { Std. } \\
\text { Error }\end{array}$ & $\mathrm{t}$ & $\mathrm{P}_{\text {value }}$ \\
\hline $\begin{array}{l}\text { Konstanta } \\
\begin{array}{l}\text { Identify } \\
\text { Suitable }\end{array}\end{array}$ & 2.373 & 0.411 & 5.778 & 0.000 \\
$\begin{array}{l}\text { Work } \\
\text { Assign }\end{array}$ & 0.001 & 0.014 & -0.048 & 0.961 \\
$\begin{array}{l}\text { Work } \\
\text { Monitor } \\
\text { and Lead } \\
\text { to }\end{array}$ & 0.033 & 0.022 & 1.486 & 0.139 \\
$\begin{array}{l}\text { Complete } \\
\text { Work }\end{array}$ & 0.025 & 0.021 & 1.218 & 0.225 \\
$\begin{array}{l}\text { Give a } \\
\text { Sense of } \\
\text { Achievem } \\
\text { ent } \\
\text { (Personal } \\
\text { Growth) }\end{array}$ & 0.009 & 0.017 & 0.522 & 0.602 \\
\hline
\end{tabular}

Nilai Faktor $O J T=2.422+$ 0.015(total nilai item Implementasi OJT) Jadi, apabila total nilai item Implementasi OJT bertambah 1 (satu) poin, akan menambah nilai faktor OJT sebesar 0.015 dengan nilai konstanta 2.422. Dengan kata lain, hasil penelitian ini membuktikan bahwa desain variable dalam OJT memberikan pengaruh terhadap kinerja.

Kemudian dilakukan uji untuk melihat apakah indikator Identify Suitable Work, Assign Work, Monitor and Lead to Complete Work, Give a Sense of Achievement (Personal Growth) memberikan pengaruh secara signifikan terhadap nilai faktor OJT. Metode yang digunakan adalah regresi linier berganda dengan variabel dependen kolom isian Internal: On The Job Development (dukungan dan bimbingan atasan) di Form $\mathrm{B}$, sedangkan variabel independent adalah total jawaban responden per indikator di Form A.

Terlebih dahulu dilakukan pengujian serentak, yaitu pengujian signifikansi model regresi. Hipotesis yang digunakan dalam pengujian ini adalah sebagai berikut.

$\mathrm{H}_{0}$ : seluruh indikator Implementasi $O J T$ tidak berpengaruh signifikan terhadap hasil $O J T$

$\mathrm{H}_{1}$ : minimal ada 1 indikator yang berpengaruh signifikan terhadap hasil $O J T$

Taraf signifikan $: \alpha=0.05$
Jurnal Psibernetika

Vol.12 (2): 80 - 89. Oktober 2019

p-ISSN: 1979-3707

e-ISSN: 2581-0871

Daerah kritis $: \mathrm{H}_{0}$ ditolak jika $\mathrm{P}_{\text {value }}$ $<\alpha$ atau $\mathrm{F}_{\text {hitung }}>\mathrm{F}_{\text {tabel }}$

Dengan $\mathrm{F}_{\text {tabel }}=\mathrm{F}_{(0.95,4,189)}=0,177$

Tabel 5. Indeks Regresi Per Variabel

Berdasarkan tabel diatas diketahui bahwa yang memiliki pengaruh signifikan terhadap model tersebut adalah nilai konstanta. Hal ini menunjukkan bahwa desain dari 4 variabel tersebut tidak dapat berdiri sendiri dalam memberikan kontribusi kepada hasil OJT, dengan kata lain 4 variabel tersebut harus menjadi satu kesatuan dalam mendukung kinerja.

\section{Pembahasan}

Berdasarkan hasil uji validitas dan reliabilitas alat ukur yang digunakan untuk dapat menguji IV dan DV dalam penelitian ini dengan menggunakan teknik statistik alpha cronbach, internal consistency pearson product moment, dan analisa faktor ditemukan hasil yang sangat valid dan reliabel dengan indeks alpha cronbach di atas 0.9 dan total internal consistency di atas 0.8. Dengan demikian, alat ukur ini dapat dipercaya untuk mengukur implementasi OJT dan pengaruhnya terhadap kinerja serta hasil analisanya dapat dipercaya sebagai faktor untuk mengambil keputusan bagi pihak manajemen.

Dari uji normalitas dan homogenitas diperoleh hasil bahdwa data bersifat homogen dan terdistribusi normal sehingga dapat dilanjutkan uji statistik parametrik dengan menggunakan teknik regresi. Hasil perhitungan distribusi frekuensi menunjukkan bahwa implementasi OJT pada PT XYZ sudah berjalan sebesar 70.51 $\%$ yang berarti bahwa hasil training yang diperoleh telah di implementasikan dalam pekerjaan sehari-hari.

Adapun desain variabel implementasi OJT yang dianggap telah berjalan baik yakni pada variabel Identify Suitable Work sebesar $72.5 \%$ artinya karyawan merasa bahwa selama ini atasan atau mentor mereka telah memberikan tugas yang sesuai dengan kebutuhan mereka. Hal ini sejalan dengan penelitian (Ginsberg, 1997) bahwa training akan memberikan hasil yang baik apabila disesuaikan dengan kebutuhan 
karyawan. Hasil ini juga sejalan dengan hasil penelitian (Karim, Huda, \& Khan, 2012) dimana training seharusnya dapat membantu karyawan untuk mendapatkan pandangan yang jelas terhadap apa yang mereka kerjakan

Namun masih ada desain variabel yang belum diimplementasikan dengan baik yakni variabel Give a Sense of Achievement (Personal Growth) dengan persentase $67,842 \%$. Berdasarkan hasil FGD dan jawaban responden pada Angket di form B, hal ini terjadi karena atasan sudah take it for granted atau menganggap jika tugas sudah selesai itu memang sudah bagian dari tanggung jawab, namun melupakan bahwa penugasan dalam OJT itu penting untuk melakukan semua tahap termasuk tahap terakhir ini agar karyawan memperoleh masukan akan pengembangan dirinya. Hal ini sejalan dengan penelitian dari (Karim et al., 2012) bahwa "Feedback is very important ingredient in the evaluation process. Employees should be communicated with their performance during and after the training".

Berdasarkan hasil uji regresi serentak menunjukkan hasil yang signifikan dan positif antara OJT terhadap kinerja. Hal ini menunjukkan bahwa desain OJT memang memiliki dampak yang signifikan terhadap peningkatan kinerja. Hal ini sejalan dengan banyak penelitian lain terkait peran training terhadap kinerja seperti penelitian (Iftikhar \& Din, 2009) yang menunjukkan hasil siginifikan antara peran training and development terhadap peningkatan kinerja.

Hal yang perlu dikembangkan dalam penelitian berikutnya adalah memperbanyak jumlah responden agar keterwakilan populasi pada sampel lebih akurat. Peneliti juga dapat melakuan pada beberapa perusahaan atau industri sehingga hasil penelitian lebih dapat digeneralisir pada populasi yang lebih luas

\section{SIMPULAN}

Berdasarkan hasil penelitian dapat disimpulkan indeks validitas dan reliabiltas alat ukur sebesar 0.9 sehingga alat ukur dapat dinyatakan valid dan reliabel, artinya data yang diperoleh dari hasil pengisian instrumen ukur dapat dipercaya untuk pengambilan keputusan. Sebaran data bersifat homogen dan terdistribusi normal, artinya hasil uji statistik bersifat parametrik dan dapat digeneralisasikan pada populasi di TMMIN.

Berdasarkan hasil analisis statistik deskriptif, persentase implementasi kompetensi OJT adalah sebesar 70,51\%. Hasil ini mengkonfirmasi data yang diperoleh dari FGD GM dimana berdasarkan pengamatan para GM yang menjadi responden, implementasi FGD masih sekitar $70 \%$. Artinya, saat ini implementasi OJT sudah cukup baik meskipun belum ideal.

Hasil distribusi frekuensi pada masing-masing indikator menunjukkan bahwa persentasi kompetensi yang dipersepsikan sudah diimplementasikan oleh $72.5 \%$ responden adalah identify suitable work dan yang paling rendah adalah give sense of achievement sebesar $67,8 \%$.

Hasil uji regresi menunjukkan bahwa terdapat pengaruh yang signifikan dan positif antara implementasi kompetensi OJT dengan kinerja. OJT hanya menunjukkan pengaruh jika keseluruhan kompetensi diimplementasikan namun tidak berpengaruh signifikan jika berdiri sendirisendiri.

OJT sudah dipahami sebagai proses untuk menginternalisasikan nilai PT XYZ.Data menunjukkan bahwa responden paling banyak mengenal OJT melalui training, artinya OJT hanya dipahami sebagai proses setelah training bukan merupakan bagian dari pekerjaan keseluruhan. Hal ini sejalan dengan hasil FGD dari GM dimana beberapa responden menyatakan bahwa OJT diasosiasikan hanya proses formal setelah training, bukan menjadi proses yang seharusnya ada dalam konteks kerja keseharian.

Berdasarkan hasil angket mengenai indikator - step dalam OJT yang paling mendukung kinerja, maka ditemukan hasil terbanyak menyatakan bahwa identifikasi tugas yang sesuai sebagai indikator yang paling mendukung pencapaian kinerja. Hal ini perlu menjadi perhatian manajemen 
Versi Online: http://journal.ubm.ac.id/index.php/psibernetika DOI: http://dx.doi.org/ 10.30813/psibernetika.v12i2.1752 Hasil Penelitian

dalam rangka mengembangkan implementasi OJT ke depannya.

\section{DAFTAR PUSTAKA}

Abdul, R., Khan, G., Khan, F.A., \& Khan, M.A. (2011). Impact of training and development on organizational performance. Global Journal of Management and Business Research, 11(7), 1-6.

Amstrong, M. (2000). Human resource management practice $\left(8^{\text {th }}\right.$ ed.). London: Kogan.

Bramley, P. (2003). Evaluating training ( $2^{\text {nd }}$ ed.). UK: CIPD UK.

Bullock. (2012). Professional development for your employees. Diambil dari http://www.scontrino-powell.com/ 2012/professional-development-foryour-employees-a-sound-investment/

Ginsberg, L. (1997). Training for the long haul. Computer Shopper, 17(4), 1514.

Iftikhar, A., \& Din, G.S. (2009). Evaluating training and development. Pakistan: Gomal Medical College and Gomal University.

Karim, M. R., Huda, K. N., \& Khan, R. S. (2012). Significance of training and post training evaluation for employee effectiveness: An empirical study on Sainsbury's supermarket Ltd. International Journal of Business and Management, 7(18), 141-148.

Kirkpatrick Level 3 Survey Questions. (n.d.).

Lee, C., Esen, E., \& DiNicola, S. (2017). Employee job satisfaction and engagement: The doors of opportunity are open. Diambil dari https://www.shrm.org/hr-today/ trends-and-forecasting/research-andsurveys/pages/2017-job-satisfactionand-engagement-doors-ofopportunity-are-open.aspx

Partlow, C. G. (1996). Human-resources practices of TQM Hotels. Cornell Hotel \& Restaurant Administration Quarterly, 37(5), 67-77.

Pilbeam, S., \& Corbridge, M. (2002). People resourcing: HRM in practice
Jurnal Psibernetika

Vol.12 (2): 80 - 89. Oktober 2019

p-ISSN: 1979-3707

e-ISSN: 2581-0871

$\left(2^{\text {nd }} \quad\right.$ ed. $) . \quad$ UK: Financial times prentice hall.

Tsaur, S.H., \& Lin, Y.C. (2004). Promoting service quality in tourist hotels: The role of HRM practices and service behavior. Tourism Management, 25(4), 471-481. 